\section{Entente Scientific Literature in Central Europe during} the War.

THE chief object of my letter, "A Tribute from Prague," published in Nature of December II, I9I9, was to congratulate the Editor upon the jubilee number and to express my delight at again being able to obtain this invaluable journal after an interval of more than five years. I thought it worth while to state very briefly that this break was caused by political reasons.

The letter by Mr. Lawson published in Nature of January $I$ induces me, unwillingly, to enter a little into non-scientific details.

There is a decided difference between the point of view during the war of an interned distinguished foreigner enjoying the well-known hospitality of the inhabitants of the capital of the late Austro-Hungarian Empire and that of us Bohemians or Czechs whose country was, by the Government of the same Vienna, nearly converted into a desert, whose best men (even poets) were imprisoned and condemned to death for their regard for the Entente, and who, had the war lasted only half a year longer, would have experienced the same fate as I,500,000 Slavonic, chiefly Serbian, children in Bosnia and Herzegovina, condemned to starvation. Their parents, in so far as they were not shot down, escaped from death only by eating grass and other herbs!

No Englishman can wonder that we (Austrian) Slavs fully sympathised with the contents of the following two remarkable articles, which I select from a great number :

(I) The leader, "The War and After," published in Nature of September Io, I9I4 (p. 29). Never previously had such a fine political article been published in your columns, and I would beg readers to convince themselves that its great truth, and even prophecy, were fulfilled to the last point.

(2) An article published by Sir Oliver Lodge during the early part of the war in the Psychological Review. Sir Oliver says that there exists a Great Justice watching over the destinies of mankind who will never allow a crime to become a law. The editor of our leading daily paper introduced this view as "strange ideas of a spiritualist," and only by this trick did it escape the watchful eye of the censor. I thank Sir Oliver for this article, which kept many of my countrymen and me firm in the days of our greatest distress.

All this was known to the Austrian Government, and it is well understood why it withheld during the whole war the circulation of periodicals which contained such articles as those referred to above.

Towards the end of the war, when everyone saw that the old Monarchy was going to pieces, the AustroHungarian Foreign Office-and I assure $\mathrm{Mr}$. Lawson that I am by no means "unaware of the fact"-asked the Senate and professors of our University to fill a circular with the names of the Entente scientific journals which they would like to obtain. I denoted several journals-in the first place, Nature. I know that those belonging to the "privileged nations" obtained the journals they wished, but no notice at all was taken of my desire or that of any other Bohemian scientific institution up to the very end of the Monarchy.

Bohuslav Brauner.

Chemical Laboratory, Bohemian Úniversity, Prague, January 20.

Percussion Figures in Isotropic Solids.

Arc anthropologists will be glad to see the subject of percussion figures receiving attention in the pages of Nature (October 9 and November 20, 1919), as the NO. 2623 , VOL. IO4] figures form the basis of flint-fracture-the important factor in determining the age and origin of man. Unfortunately, the fracture cone is by no means so simple and constant in outline as one might be led to expect from what has already been advanced, and a number of factors enter into the question, such as the shape and elasticity of the percusser, the velocity of the blow, the striking angle, the perfection of surface of the percussed, its elasticity, and, above all, its varying refrangibility.

In Nature and practice we generally find that after the cone has maintained itself for a distance, the surface resolves into a cylinder in the striking plane, which is maintained for a certain varying distance; then it resolves outwards in a more conical direction, which may extend until rupture takes place; or it may even resolve again and again as before, giving rise to step-cones. Specimens before me show seven such steps. Further, from causes into which we cannot now enter, the well-known conchoidal ripplings may be set up. These may be very simple and concentric or the very reverse, and may be either apical or marginal; they pass into step-cones. Frequently the surface turns inwards, producing cylindrical fracture more or less normal to the striking plane.

Generally, with glass and flint there is another set of features in the form of stellate lines, which may be very few or numbered by hundreds. An examina. tion of these shows the cone to be a surface of revolution, and the direction of the gyrations is shown by the steps made by every radial (some dozen of these are faintly shown in Prof. Raman's illustration in Nature of October 9). These may increase in size until we get step-fracture, where the steps may be, say, $3 \mathrm{~mm}$. or $4 \mathrm{~mm}$. high. It may be noted in passing that these are the lines along which fracture in plate-glass takes place.

Perhaps the most remarkable thing about these steps is that they indicate right and left revolutions in relation to the cone. Sometimes the two hemicones coincide, and we get a perfect cone. At other times the fracture-waves overlap for a distance, giving rise to the mysterious éraillure; they may also meet in a re-entrant angle, which may become very acute, say down to $30^{\circ}$. This is only the beginning of the complications. Cones may be quite asymmetrical; one hemicone may be reduced to a plane. There are also faceted cones, shell-cones (cones in cones), and cones in cups. Then there are the phenomena of conecapture, and still greater complications of positive and negative hemicones, and multiple hemicones which by mutual capture produce large flat surfaces, and many others.

I suggest that the study involves something more than isotropics, seeing that in glass, silica, and many other substances new atomic or molecular re-arrangements set in which soon render them anisotropic or anisoclastic, and in one direction end in spontaneous disruption into forms which call for mathematical explanation quite as much as, and indeed more than, simple percussion figures in ideal isotropes; and, on the other hand, colloids pass into crystals where both optical and dynamical properties vary according to the lines along which the alterations take place.

St. I.eonards-on-Sea.

W. J. LEWIS ABвotT.

\section{Change of Colour in Plumage of Captive "Sun-birds" or "Honey-suckers."}

We have had considerable success at the Zoological Gardens here in keeping in health nine varieties of "sun-birds" or, as locally known," honey-suckers," 